\title{
Focus on blunt abdominal trauma
}

\author{
A. B. Peitzman ${ }^{1}$
}

Received: 11 March 2015 / Accepted: 7 April 2015 / Published online: 23 April 2015

(C) Springer-Verlag Berlin Heidelberg 2015

The management of blunt abdominal trauma has changed dramatically over the past 3 decades. The introduction and promulgation of computed tomography (CT) provided a diagnostic test providing both sensitive and specific information. CT documented the presence and quantity of hemoperitoneum as well as the specific organ injured (which we graded). This advance allowed the safe practice of nonoperative management of blunt solid abdominal organ injury. The progress made in interventional radiology with both diagnosis and embolization techniques provided another tool to facilitate safe nonoperative management of abdominal organ injury. These modalities have also facilitated the nonoperative management of the complications of observation of blunt injuries; such as percutaneous drainage of an abscess or endoscopic retrograde cholangiopancreatography (ERCP) for diagnosis and treatment of injury to the biliary or pancreatic ducts. We have provided four review articles addressing "What's new?" in the management of blunt injury to the spleen [1], liver [2], pancreas [3] and kidney [4]. These articles have centered on references from the past 10-15 years, as well as seminal articles. We hope that you find them to be useful.
Conflict of interest Andrew B. Peitzman declares that he has no conflict of interest.

Compliance with ethical requirements This work is in compliance with ethical requirements. Andrew B. Peitzman declares that this is an editorial that includes no studies on humans or animals.

\section{References}

1. Watson GA, Hoffman MK, Peitzman AB. Nonoperative management of blunt splenic injury: what is new? Eur J Trauma Emerg Surg. 2015 (this issue). doi:10.1007/s00068-015-0520-1.

2. Ward J, Alarcon L, Peitzman AB. Management of blunt liver injury: what is new? Eur J Trauma Emerg Surg. 2015 (this issue). doi:10.1007/s00068-015-0521-0.

3. Potoka DA, Gaines BA, Leppäniemi A, Peitzman AB. Management of blunt pancreatic trauma: what's new? Eur J Trauma Emerg Surg. 2015 (this issue). doi:10.1007/s00068-015-0510-3.

4. Kautza B, Zuckerbraun B, Peitzman AB. Management of blunt renal injury: what is new? Eur J Trauma Emerg Surg. 2015 (this issue). doi:10.1007/s00068-015-0516-x.
A. B. Peitzman

peitzmanab@upmc.edu

1 University of Pittsburgh, Pittsburgh PA, USA 